\title{
Effect of cytochalasin types on the production of heterozygous parthenogenetic porcine embryos and the isolation of putative parthenogenetic embryonic stem cells
}

\author{
Ivan Vassiliev*, Anders Tsui, Wan Xian Kang, Stephen Mcllfatrick and Mark B. Nottle \\ *Correspondence: ivan.vassiliev@adelaide.edu.au

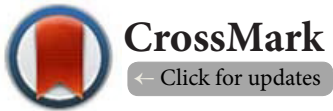

Reproductive Biotechnology Group, Discipline of Obstetrics and Gynaecology, School of Paediatrics and Reproductive Health and Centre for Stem Cell Research, Robinson Institute, University of Adelaide, Adelaide, Australia.

\begin{abstract}
Parthenogenetic embryos have been suggested as an alternative source of embryonic stem cells (ESCs). The present study was undertaken to determine the efficiency with which porcine heterozygous parthenotes could be produced using cytochalasin B (CB) or cytochalasin D (CD) and whether parthenogenetic ESCs (pESCs) could be isolated from these. Cleavage rate was lower and fewer embryos developed to the blastocyst stage in the $\mathrm{CB}$ group compared with the CD group. The number of primary outgrowths obtained was also lower in the CB compared with the CD group. No primary lines were isolated from embryonal outgrowths in the $\mathrm{CB}$ group. In contrast, primary cell lines were derived from these in the CD group. These lines survived vitrification and warming, resulting in established cell lines, which maintained a characteristic ESC morphology and expressed the pluripotent markers Oct4 and Nanog following repeated passaging. Putative pESC lines could also be directly differentiated to cell types representative of all three germ layers.
\end{abstract}

Keywords: Parthenotes, porcine, heterozygosity, heterozygous ESC

\section{Introduction}

Embryonic stem cells (ESCs) are pluripotent cells derived from epiblast of blastocysts $[\mathbf{1}, \mathbf{2}]$. These cells have the capacity for unlimited self-renewal and can be directed to differentiate into all cell types in the body. As such, ESCs are thought to hold considerable potential for treating a range of degenerative diseases and injuries [3]. However, the isolation of ESCs from human embryos raises religious, social, and ethical issues because it involves the destruction of embryos, which has limited research in this area. As such, alternative sources of ESCs are being examined to overcome these issues, including the isolation of ESCs from parthenogenetic embryos. Parthenogenetic ESCs ( $p E S C s$ ) have been isolated for various mammalian species, but have only been extensively characterized in mice [4-6]. This has included directed differentiation into cell types representative of all three germ layers and the production of chimeric mice and the demonstration of germline transmission $[6,7]$.

Mammalian parthenogenetic embryos (parthenotes) are produced by the artificial activation of oocytes. These are normally diploidized using a range of chemicals to inhibit polar body extrusion. Depending on when polar body extrusion is inhibited, two types of diploid parthenotes can be produced. The first polar body contains homologous chromosomes while second polar body contain sister chromatids. When meiosis is blocked at metaphase I the oocyte remains tetraploid (4n), homologous chromosomes remain unseparated, the first meiotic division does not occur and the first polar body is not extruded. Following activation and the resumption of meiosis the second polar body containing sister chromatids is extruded. These diploid parthenotes are heterozygous because they contain maternal and paternal (biparental) alleles. In contrast, during the inhibition of polar body extrusion after activation at metaphase II the sister chromatids remain unseparated and as result the homozygous parthenotes are produced (uniparental genome).

While homozygous parthenotes have been produced for a range of species, heterozygous parthenotes have only been produced in mice and pigs $[5,8,9]$. With that heterozygous parthenotes derived from the oocytes of the same donor are practically a clones of donor of oocytes because have the same genome as donor of oocytes but with different gene arrangement because of cross over [9]. While a range of diploidization agents have been reported the majority of studies have used cytochalasin B (CB) to inhibit polar body extrusion. The cytochalasins are cell-permeable toxins, which cause actin filament disruption and inhibit actin polymerization preventing the resumption of meiosis and polar body extrusion. However, CB has been shown previously to be cytotoxic. In the pig oocytes are exposed to CB for a relatively long time (22h) in order to produce heterozygous parthenotes which may a detrimental effect on the viability of parthenotes which in turn may affect the ability to isolate ESCs from these [8]. In contrast, 
Vassiliev et al. Stem Cell Biology and Research 2014,

http://www.hoajonline.com/journals/pdf/2054-717X-1-2.pdf

$\mathrm{CD}$ is thought to be less cytotoxic [10].

While homozygous parthenogenetic ESC lines have been isolated for a range of species, ESC lines from heterozygous embryos have been isolated in mice only [5]. The aim of the present study therefore was to determine the efficiency with which $C B$ and $C D$ could be used to generate heterozygous parthenotes in pigs and whether pESCs could be isolated from these using a method developed previously by us for the isolation of porcine ESCs from in vitro produced and somatic cell nuclear transfer (SCNT) embryos [11-13].

\section{Materials and methods}

All chemicals were purchased from Sigma-Aldrich unless otherwise stated.

\section{Oocyte collection and maturation}

Sow oocytes were collected and matured in vitro as described previously by Beebe et al., [14] with minor modifications. Ovaries were transported from a local abattoir to the laboratory in $0.9 \%$ sodium chloride solution at between $33^{\circ} \mathrm{C}$ and $37^{\circ} \mathrm{C}$. Cumulus-oocyte complexes (COCs) were matured for $46 \mathrm{~h}$ in BOMED medium [15] under mineral oil in a humidified atmosphere of $5 \% \mathrm{CO}_{2}, 5 \% \mathrm{O}_{2}$ and $90 \% \mathrm{~N}_{2}$ at $38.5^{\circ} \mathrm{C}$. BOMED medium consisted of Medium 199 (Life technologies, USA) supplemented with $0.5 \mathrm{mM}$ cysteamine, $0.1 \mathrm{mg} / \mathrm{ml}$ sodium pyruvate, $75 \mu \mathrm{g} / \mathrm{ml}$ penicillin $\mathrm{G}, 50 \mu \mathrm{g} / \mathrm{ml}$ streptomycin sulphate, $5 \mu \mathrm{g} / \mathrm{ml}$ insulin, $5 \mu \mathrm{g} / \mathrm{ml}$ follicle stimulating hormone ( $\mathrm{FSH}$ ), $10 \mathrm{ng} / \mathrm{ml}$ recombinant human epidermal growth factor (EGF) and $10 \%$ sow follicular fluid.

\section{Heterozygous parthenotes production}

Heterozygous parthenotes were produced as described previously with minor modifications [8] by treating in vitro maturing oocytes with $5 \mu \mathrm{g} / \mathrm{ml} \mathrm{CB}$ or $2.5 \mu \mathrm{g} / \mathrm{ml} \mathrm{CD}$ at $20 \mathrm{~h}$ of maturation for 22 hours (Figure 1). Oocytes were freed of cumulus cells by brief exposure to $0.1 \%$ hyaluronidase and manual pipetting and were activated 3 hours after treatment as previously described [16]. Before activation, oocytes were examined and those with polar bodies were excluded from experiment to avoid of the inclusion of homozygous haploid parthenotes. Denuded oocytes were activated by two $60-\mu \mathrm{sec}$ $150 \mathrm{~V} / \mathrm{mm}$ direct current pulses with $1 \mathrm{sec}$ apart using the Electro Cell Manipulator 2001 (BTX). Activated oocytes were cultured overnight and examined again for the presence of

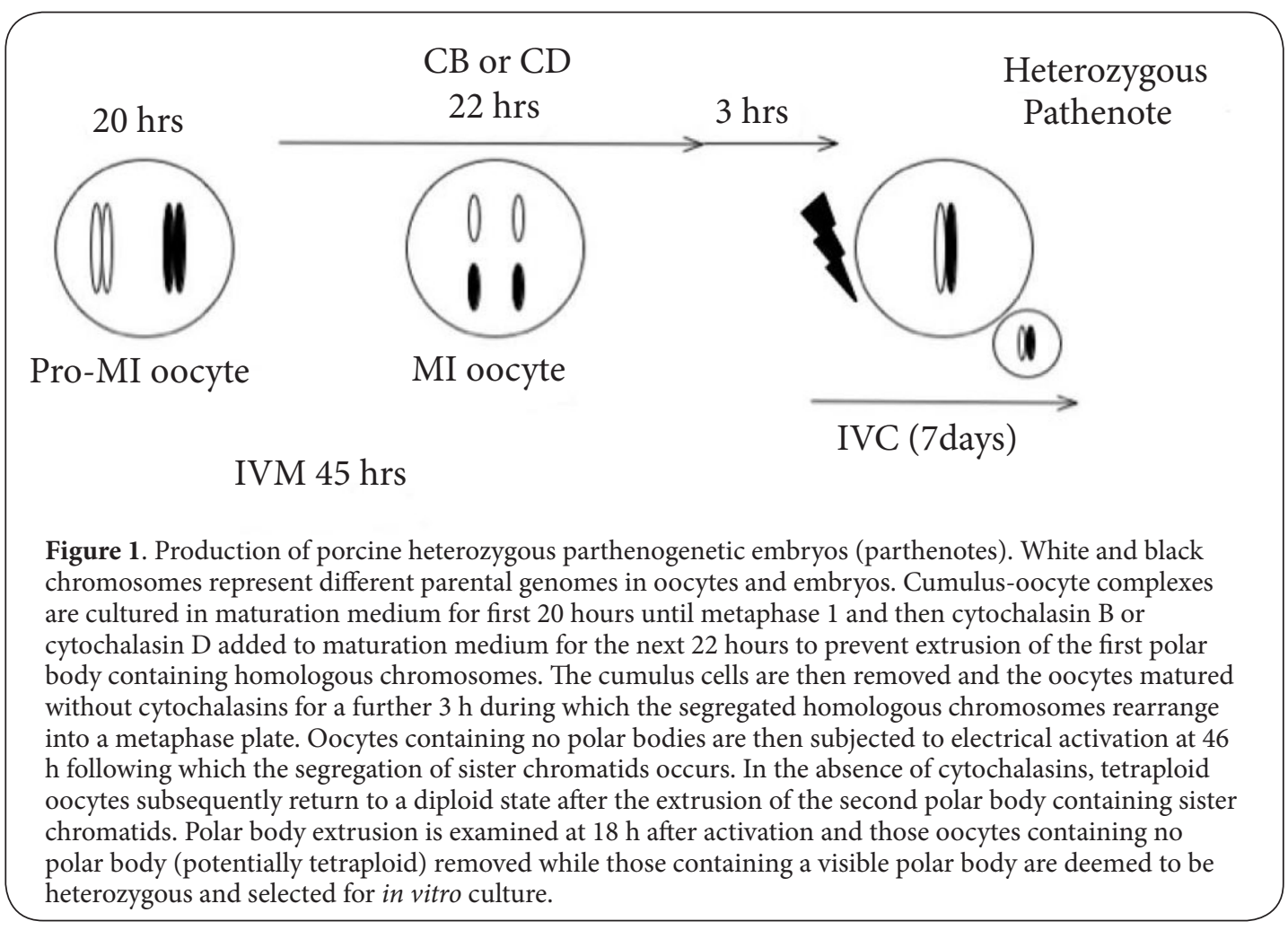

polar bodies. Oocytes without polar bodies were excluded from experiment to avoid the inclusion of tetraploid parthenotes.

In vitro embryo culture

Parthenogenetic embryo culture was conducted in a two- stage system as described previously by Beebe et al., [16] Briefly, embryos were cultured in 50- $\mu$ l droplets of modified NCSU23from days 0 to 3 and in 45- $\mu$ droplets of standard NCSU23 [17] from days 4 to 7 under mineral oil in a humidified atmosphere of $5 \% \mathrm{CO}_{2^{\prime}} 5 \% \mathrm{O}_{2}$ and $90 \% \mathrm{~N}_{2}$ at $38.5^{\circ} \mathrm{C}$. The modified 
NCSU23 (NCSU23-plg-neaa) contained $0.2 \mathrm{mM}$ pyruvate, 5.7 $\mathrm{mM}$ lactate, $0.6 \mathrm{mM}$ glucose and 1\% MEM non-essential amino acids (Life technologies, USA) whereas the standard NCSU23 (NCSU23-neaa-eaa) contained $5.6 \mathrm{mM}$ glucose, 1\% MEM nonessential and essential amino acids (Life technologies, USA). Cleavage rate was assessed on day 3 when the culture medium was changed, and only embryos with more than 2 cells were cultured further. Ten percent heat inactivated foetal bovine serum (FBS) was added on early day 5 and blastocyst rate was assessed on day 7 . Only expanded or hatched blastocysts with a defined inner cell mass and thin zona pellucida were selected for pESC isolation.

\section{Parthenogenetic embryonic stem cell isolation}

pESC were isolated from parthenotes as described previously [11-13]. Day-7 blastocysts with zona pellucidae removed were gently pressed onto mitotically inactivated MEF feeder layers using a 30-gauge syringe and cultured in porcine ESC isolation medium for 6-12 days to obtain embryonal outgrowths. The isolation medium consisted of aMEM medium withGlutaMAX-I (Life technologies, USA) supplemented with $10 \%$ KnockOut serum replacement (SR), 1\% MEM non-essential amino acids, $1 \%$ sodium pyruvate, $1 \%$ insulin-transferrin-selenium (ITS), 55 $\mu \mathrm{M}$ 2-mercaptoethanol, $10 \mathrm{ng} / \mathrm{ml}$ recombinant human basic fibroblast growth factor (bFGF), $10 \mathrm{ng} / \mathrm{ml}$ recombinant human EGF (all from Life Technologies, USA), $10 \mathrm{ng} / \mathrm{ml}$ recombinant human Activin A (R\&D Systems, USA), 10ng/ml recombinant human leukemia inhibitory factor (LIF) and $0.5 \%$ antibioticantimycotic solution. Culture was conducted in a humidified atmosphere of $5 \% \mathrm{CO}_{2^{\prime}} 5 \% \mathrm{O}_{2}$ and $90 \% \mathrm{~N}_{2}$ at $38.5^{\circ} \mathrm{C}$. Medium was changed every 4-6 days. Putative porcine pESCs were identified according to morphological criteria described previously [11-13] including polygonal shape, 10-15 $\mu \mathrm{m}$ in diameter, a small cytoplasmic/nuclear ratio, multiple lipid inclusions in the cytoplasm and a single nucleus with multiple nucleoli. Homogenous embryonal outgrowths, which had reached 3-5 mm in diameter, were cut into $200 \mu \mathrm{m}$ square pieces and re-plated onto fresh feeder layer to passage the cells. Expanded pESC colonies were passaged repeatedly and cultured as above.

Cleavage rate, blastocyst formation rate, primary embryonal outgrowth formation rate and the efficiency with which primary pESC lines could be isolated were analyzed by Fisher's exact test with 95\% confidence interval using Graph Pad Prism 5 software (Graph Pad Software, USA).

\section{Vitrification and warming}

Porcine pESC lines were considered viable if they survived cryopreservation. pESCs were vitrified and warmed as previously described [11]. Briefly, pESC colonies were cut into pieces and vitrified using the CryoLogic Vitrification Method (CVM; CryoLogic Pty. Ltd). pESC colony pieces were held in $1 \mathrm{ml}$ of the base medium containing aMEM medium with GlutaMAX-I (Life technologies, USA) supplemented with 25
mM HEPES buffer solution (Life technologies, USA) and $20 \%$ FBS. 8-10 pieces at a time were initially washed in fresh base medium, then in $1 \mathrm{ml}$ of the base medium supplemented with $10 \%$ dimethyl sulfoxide (DMSO) and 10\% ethylene glycol for 1 min and in $1 \mathrm{ml}$ of the base medium supplemented with $20 \%$ DMSO, 20\% ethylene glycol and $0.3 \mathrm{M}$ sucrose (vitrification medium) for $20 \mathrm{sec}$, loaded in an approximately $3 \mu \mathrm{l}$ droplet of the vitrification medium onto a nylon hook and eventually vitrified by touching the hook onto the surface of a metal block which had been cooled by liquid nitrogen. The nylon hooks were then covered with cooled plastic sleeves, plunged into liquid nitrogen and stored. For warming pESC colony pieces, the vitrified droplets were dissolved and washed in $1 \mathrm{ml}$ of the base medium supplemented with $0.2 \mathrm{M}$ sucrose for $1 \mathrm{~min}$. The colony pieces were then washed once in $1 \mathrm{ml}$ of the base medium supplemented with $0.1 \mathrm{M}$ sucrose and twice in $1 \mathrm{ml}$ of the base medium, with $5 \mathrm{~min}$ for each wash. The warmed pieces were plated onto fresh feeder layer.

\section{Immunofluorescence for co-expression of pluripotent markers}

pESC colonies were fixed and permeabilized with $4 \%$ paraformaldehyde (PFA) and $0.3 \%$ saponin (Calbiochem, Germany) for 30 min, washed 3 times with DPBS (Life technologies, USA) supplemented with $0.3 \%$ saponin, blocked with DPBS supplemented with $0.3 \%$ saponin and $10 \%$ normal donkey serum (blocking solution) for $30 \mathrm{~min}$, incubated with primary antibodies diluted in blocking solution overnight at $4^{\circ} \mathrm{C}$, washed 3 times, incubated with secondary antibodies diluted in blocking solution for $1 \mathrm{~h}$ in the dark, washed 3 times and mounted with Slow Fade Gold antifade reagent with DAPI (Life technologies, USA). The primary antibodies were goat antiOct3/4 (1:100 dilution; sc-8628, Santa Cruz Biotechnology) and rabbit anti-Nanog (1:200 dilution; Merk-Millipore, Germany). The secondary antibodies were donkey anti-goat lgG-FITC (1:200 dilution; sc-2024, Santa Cruz Biotechnology) and goat anti-rabbit Ig-TXRD (1:200 dilution; Southern Biotech, USA). MEFs were used as negative control. Fluorescent images were captured using Leica TCS SP5 confocal laser scanning microscope (Leica Microsystem, Germany).

\section{In vitro differentiation}

Heterozygous pESC lines were further examined in terms of their ability to undergo directed differentiation in vitro into cells representative of mesoderm, endoderm and ectoderm germinal layers. Directed differentiation was conducted according to protocols described previously [11-13]. To induce endo-mesoderm differentiation, pESC colonies were initially cultured in porcine ESC medium with an increased concentration of Activin A (100 ng/ml; R\&D Systems) for 6-7 days.

For endoderm differentiation, endo-mesoderm differentiation medium was replaced with RPMI 1640Medium (Life technologies, USA) with low (11 mM) glucose concentration 
Vassiliev et al. Stem Cell Biology and Research 2014,

http://www.hoajonline.com/journals/pdf/2054-717X-1-2.pdf

doi: 10.7243/2054-717X-1-2

supplemented with $2 \%$ SR (Life technologies, USA), $10 \mathrm{mM}$ nicotinamide, $10 \mathrm{nM}$ exendin 4 (Abbiotec, USA) and $50 \mathrm{ng} /$ $\mathrm{ml}$ insulin growth factor II (IGF-II; Life technologies, USA) for another 15-25 days of culture. A few days before fixation the glucose concentration in medium was increased to 25 $\mathrm{mM}$ when the cells started to cluster. After culture, colonies were fixed and permeabilized as described above to perform Immunofluorescence for pancreatic and duodenal homeobox 1 (PDX-1). The primary antibody was rabbit anti-PDX-1 (1:500 dilution; Merk-Millipore, Germany) and the secondary antibody was donkey anti-rabbit lgG-Alexa 546 (1:200 dilution; A11055, Invitrogen). The F-actin of cell membranes was stained with Alexa Fluor-488 Phalloidin (Life technologies, USA). Fluorescent images were captured using Leica TCS SP5 confocal laser scanning microscope (Leica Microsystem, Germany).

For mesoderm differentiation into adipocytes, pESCs were also cultured with high concentration of activin $A$ as described above. pESCs were then cultured in a 3-5 times rotation of adipogenic induction (Al) medium for 3 days, then adipogenic maintenance (AM) medium for 1 day. Al medium consisted of DMEM medium (Life technologies, USA) supplemented with $10 \% \mathrm{FBS}, 0.6 \%$ antibiotic-antimycotic solution, $0.5 \mathrm{mM}$ methyl-isobutylxanthine (IBMX), $100 \mathrm{mM}$ indomethacin, $1 \mathrm{mM}$ dexamethasone and $10 \mu \mathrm{g} / \mathrm{ml}$ insulin. AM medium consisted of DMEM medium (Life technologies, USA) supplemented with $10 \% \mathrm{FBS}$ and $10 \mu \mathrm{g} / \mathrm{ml}$ insulin. Colonies were then maintained in AM medium for 4-7 days prior to fixation. Colonies were fixed in $4 \%$ paraformaldehyde and stained with Oil Red $\mathrm{O}$. Nuclei were then counterstained with haematoxylin. The colonies were analyzed using Nikon Eclipse TS100 inverted microscope (Nikon Instruments Inc., Japan).

For ectoderm differentiation, $\mathrm{pESCs}$ were differentiated into neural-like cells by culturing in neural differentiation medium, which consisted of KnockOut ${ }^{\mathrm{TM}}$ DMEM/F12 supplemented with $2 \% \mathrm{SR}, 1 \% \mathrm{~N} 2$ supplement, $55 \mathrm{mM} 2$-mercaptoethanol and 10 $\mathrm{ng} / \mathrm{ml} \mathrm{bFGF} \mathrm{(all} \mathrm{from} \mathrm{Life} \mathrm{technologies,} \mathrm{USA)} \mathrm{for} 30$ days. pESC colonies were then fixed and permeabilised as described for immunofluorescence analysis above. Expression of nestin was used as an indicator of neural differentiation. The primary antibody was goat anti-nestin IgG (1:200 dilution; Santa Cruz Biotech, USA) and secondary antibody was donkey anti-goat IgG-Alexa Fluor ${ }^{\circledR} 647$ (1:200 dilution; Life technologies, USA). Fluorescence image analysis was performed using Leica TCS SP5 Confocal Microscope (Leica Microsystem, Wetzlar, Germany).

\section{Results and discussion}

The present study was undertaken to determine the efficiency with which porcine heterozygous parthenotes could be produced using $C B$ and $C D$ and the efficiency with which heterozygous $\mathrm{pESC}$ s could be isolated from these. To confirm heterozygosity previous researchers $[5,9]$ have analyzed parthenogenetic embryos obtained from hybrid females of two mice strains with distinguishable protein isoforms or single nucleotide polymorphism profiles and compared these with their parents In contrastourstudy used abattoir derived oocytes from predominately Large White $x$ Landrace sowswhich also contain infusions of Duroc. This unknown mixed parentage did not allow us to determine which alleles are maternal or paternal in origin or the level of heterozygosity using single nucleotide polymorphism array or microsatellite analysis. Nevertheless having demonstrated the concept in mice, it is reasonable to assume that the suppression of the first polar body extrusion in porcine oocytes also results in the production of heterozygous parthenotes.

\section{Effect of cytochalasin B and D on the production of heterozygous parthenotes and the isolation of pESCs}

The effect of $C B$ and $C D$ on the development of heterozygous porcine parthenotes and the efficiency with which $\mathrm{pESC}$ lines could be derived from these is shown in (Table 1). A total 816 oocytes were treated with $C B$ and 872 oocytes treated with $C D$. Cleavage rate was significantly lower in $\mathrm{CB}$ group compared with CD group ( 58.6 vs. $88.4 \%$; $p<0.001$ ). In both groups, oocytes were able to develop to the blastocysts stage at day 7 of culture (Figure 2A). However blastocyst development rate was significantly lower in $C B$ group compared with the $C D$ group (39.5 vs. $47.2 \%$; $p<0.01$ ).

Blastocysts in both groups were able to form homogeneous

Table 1. The effect of cytochalasin B and D on the production of heterozygous parthenotes and the isolation of parthenogenetic ESCs.

\begin{tabular}{|c|c|c|c|c|c|c|}
\hline Chemicals & Activated oocytes (\%) & Cleaved oocytes (\%) & $\begin{array}{l}\text { Blastocysts produced } \\
\text { and plated }(\%)\end{array}$ & $\begin{array}{l}\text { Primary ESC } \\
\text { outgrowths (\%) }\end{array}$ & $\begin{array}{l}\text { Primary ESC } \\
\text { lines (\%) }\end{array}$ & $\begin{array}{l}\text { Established ESC } \\
\text { lines (\%) }\end{array}$ \\
\hline Cytochalasin B & 816 & $478(58.6)^{\mathrm{a}}$ & $189(39.5)^{\mathrm{a}}$ & $5(2.6)^{\mathrm{a}}$ & 0 & 0 \\
\hline Cytochalasin D & 872 & $771(88.4)^{c}$ & $364(47.2)^{\mathrm{b}}$ & $39(10.7)^{c}$ & $8(2.2)$ & $2(0.5)$ \\
\hline
\end{tabular}

Values with different superscripts within a column are significantly different. a and b different significantly with $\mathrm{P}$ value $<0.01$ : a and $\mathrm{c}$ different significantly with $\mathrm{P}$ value $<0.001$.

primary embryonal outgrowths. However embryonal out growth rate was lower in in the $C B$ group compared with the $C D$ group $(p<0.001)$. Only five $(2.65 \%)$ primary outgrowths were established in CB group after plating 189 blastocysts, whereas in CD group 39 (10.7\%) of 364 plated blastocysts were able to form primary outgrowths (Figure 2B) in both groups 
embryonal outgrowths were morphologically homogeneous consisting entirely of pESCs None of theoutgrowths in CB groupsurvived to passage two to form primary cell lines. In the $C D$ group eight parthenotes gave rise to the primary celllines (2.2\%) and twoof these(0.5\%) survived vitrification/ warning resulting inestablished heterozygous pESC lines. pESCs had characteristic ESC morphology (Figure 2C). As described previously by us for ESCs isolated from in vitro produced and somatic cell nuclear transfer (SCNT)embryos $[11,13]$ namely ESC wererelatively smallin size (10-15 $\mu \mathrm{m}$ in diameter) and polygonal in shape. The nucleus occupied practically all of the volume of the cell and hold multiple nucleoli. Cells also have numerous lipid inclusions in the cytoplasm.

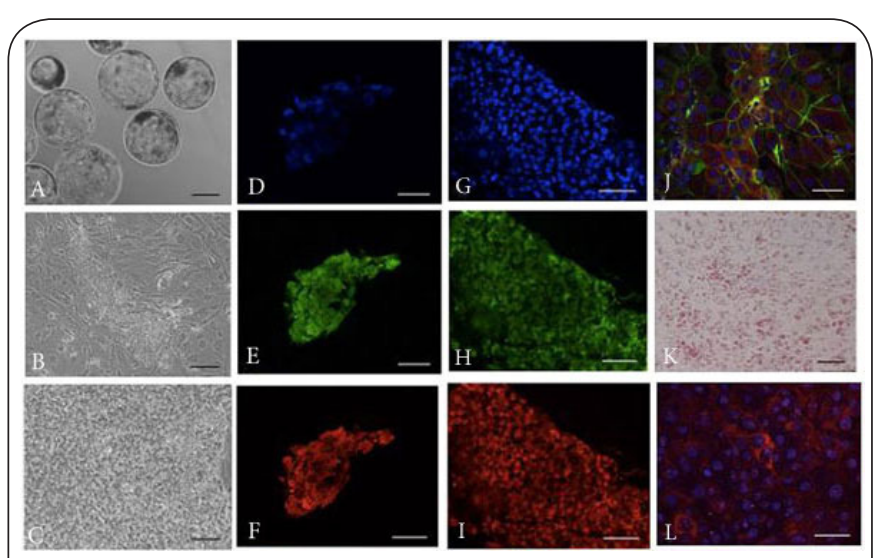

Figure 2. Production of porcine heterozygous parthenotes and characterization of ESC lines. (A) Porcine heterozygous parthenotes produced after treatment of oocytes with cytochalasin D. (B) Morphologically homogeneous primary embryonal outgrowth from heterozygous parthenote produced using cytochalasin D 5 days after plating. (C) Established porcine pESCs at passage 5 isolated from heterozygous parthenotes produced using cytochalasin D. Primary embryonal outgrowths (D-E) and established heterozygous pESCs (G-I) co-expressed the pluripotency markers Oct-4 (green) and Nanog (red). Nuclei are stained with blue (DAPI). Heterozygous pESCs could be directly differentiated into representative of all three germ layers. Analysis of endoderm differentiation $(\mathbf{J})$ demonstrated that under differentiation conditions pdx-1 (red) was found in cytoplasm and in the nuclei nuclei (small red dots in nuclei) of differentiating cells indicating the migration of $\mathrm{pdx}-1$ from cytoplasm into the nucleus (blue) in response to changing glucose concentrations. Cell membranes stained green. Mesodermal differentiation (K) resulted in formation of adipocytes with fat droplets stained with red. Ectodermal differentiation $(\mathbf{L})$ resulted in the formation of nestin-positive cells (red). Bar in Fig. 2K: $50 \mu \mathrm{m}$. Bars in all others images: $100 \mu \mathrm{m}$

\section{Characterization of heterogeneous parthenogenetic ESC lines}

Immunofluorescence analysis of one of the primary embryonal outgrowths and established cell line isolated from it at passage 5 demonstrated that all cells of outgrowth (Figures 2D and 2F) and cell line (Figures $\mathbf{2 G}$ and $\mathbf{2}$ I) co-expressed of the pluripotent markers Oct4 and Nanog. Established heterozygous pESC lines were maintained in culture until passage eight and then were successfully differentiated into cell types representative of all three germ layers. Endoderm lineage differentiation of heterozygous ESC into pancreatic islet progenitor cells resulted in appearance of cells expressing pdx-1-protein that is involved in the early development of the pancreas and plays a major role in glucose-dependent regulation of insulin gene expression. Although pdx 1 is an insulin transcription factor, its localization in cells is glucose-dependent. When cells are cultured in media containing low glucose pdx 1 is localized in cytoplasm, whereas following an increase in glucose concentration pdx1 migrates to the nucleus [18]. In our experiments endoderm differentiation was induced in medium containing low glucose to promote cell expansion. These cells were then cultured in high glucose for a few days immediately prior to fixation resulting in the presence of $\mathrm{pdx}$ 1 protein in both compartments as described previously by us for ESCs isolated from in vitro produced and somatic cell nuclear transfer embryos [11,13].

As result pdx-1 protein was detected both in cytoplasm and nuclei (Figure $\mathbf{2} \mathbf{J}$ ), and this testifies the beginning of the migration of pdx-1 into nucleus as expected.Culture in mesodermal lineage differentiation medium containing adipogenic factors produced adipocytes (Figure $\mathbf{2 K}$ ) as confirmed with Oil Red O staining.Culture of ESCs in neural differentiation medium for 30 days produced nestin-positive neural precursor cells, which had diffusive cytoplasmic staining (Figure 2L). Besides its cytoplasmic localization, nestin also was found in nuclei. This is not surprising because ESC is vulnerable to neoplastic formation and during neuronal differentiation can form cells, which share properties with neural neoplastic cells. Such cells can exhibit both nuclear and nucleolar localization of nestin [19] which can interact with DNA [20].

The present study was undertaken to determine the efficiency with which porcine heterozygous parthenotes could be produced using cytochalasin B and D and the efficiency with which heterozygous pESCs could be isolated from these. CB is commonly used for SCNT to relax the cytoskeleton and prevent the extrusion of transferred nuclei in enucleated oocytes. In contrast, CD is rarely used for this purpose. However, treatment of SCNT embryos with CB results in a significant reduction in cleavage and blastocyst rates compared with CD [21]. Similar effects were seen in our study when CB was used to produce diploidized heterozygous parthenotes. Treating oocytes for $22 \mathrm{~h}$ with CB resulted in significantly lower cleavage and blastocyst formation rates compared with that for the CD treated group. Blastocysts from CB treated group also formed primary ESC outgrowths at a significantly lower level than those from the CD treated group. Furthermore, no primary or established putative pESC lines were obtained from outgrowths in the CB group. In contrast, eight primary 
Vassiliev et al. Stem Cell Biology and Research 2014,

http://www.hoajonline.com/journals/pdf/2054-717X-1-2.pdf

and two established cell lines were isolated in the CD group. Established pESC lines had a characteristic ESC morphology and expressed Oct-4 and Nanog following repeated passaging. Furthermore, these cell lines could be directly differentiated to cell types representatives of all three germ layers.

The failure to establishcell lines from heterozygous parthenotes using $C B$ could be explained by its known cytotoxic effect in particular its ability to inhibit glucose transport across the plasma membrane not only inthe maturing oocyte but also in the surrounding cumulus cells.lt is known that cumulus cells are very important both for maintenance of developmental potential of porcine oocytes and for distribution and functionality of cortical granules and mitochondria [22]. The cytotoxic effect of $C B$ on cumulus cells may affect the cytoplasmic maturation of oocytes and developmental competence of pluripotent cells of parthenotes. In contrast, $C D$ has been shown not to interfere with glucose transport [10]. In addition, CD treated parthenogenetic oocytes show faster reorganization of cortical F-actin after artificial activation, which is critical for normal mitochondria distribution, and the transfer of these to the daughter cells during cell division compared with CB treatment [21]. However, previous attempts in our laboratory to isolate ESCs from pig homozygous parthenotes using CD have also failed (unpublished results). This suggests that level of heterozygosity may also affect the derivation of pESC lines possibly through the expression of recessive lethal and sublethal genes as well as the aberrant expression of imprinted genes [23]. This is consistent with previous attempts to isolate $\mathrm{pESCs}$ from pig homozygous parthenotes produced using ionomycin and 6-DMAP [24] or electrical activation and CB treatment [25] where isolated pESCs had limited developmental potential and a relatively short lifespan in culture. As such, we suggest that the cytotoxicity of diploidization agent and the degree of heterozygosity are important factors in the isolation of parthenogenetic ESCs.

In conclusion, we have demonstrated that CD can be used to generate heterozygous parthenotes from which putative parthenogenetic ESC lines can be established. These cells had a characteristic ESC morphology and could be differentiated to cell types representative of all three germ layers. This is the first time to our knowledge that putative ESC has been isolated from porcine heterozygous parthenotes. In contrast, ESCs could not be isolated using CB possibly because of its increased toxic effects as a consequence of the relatively long exposure time required to produce heterozygous parthenotes. Further work is required to confirm the pluripotency of these $\mathrm{pESC}$. In particular, further in vivo characterization of these cells is required including teratoma formation in immune compromised mice, chimaera production and the demonstration of germline transmission as has been demonstrated previously for homozygous mouse pESCs [6,7].

\section{Competing interests}

The authors declare that they have no competing interests.

Authors' contributions
\begin{tabular}{|l|c|c|c|c|c|}
\hline Authors' contributions & IV & AT & WXK & SM & MBN \\
\hline Research concept and design & $\checkmark$ & -- & - & -- & $\checkmark$ \\
\hline Collection and/or assembly of data & $\checkmark$ & $\checkmark$ & $\checkmark$ & $\checkmark$ & -- \\
\hline Data analysis and interpretation & $\checkmark$ & $\checkmark$ & $\checkmark$ & -- & $\checkmark$ \\
\hline Writing the article & $\checkmark$ & $\checkmark$ & $\checkmark$ & -- & $\checkmark$ \\
\hline Critical revision of the article & $\checkmark$ & -- & -- & -- & $\checkmark$ \\
\hline Final approval of article & $\checkmark$ & -- & -- & -- & $\checkmark$ \\
\hline Statistical analysis & $\checkmark$ & $\checkmark$ & $\checkmark$ & -- & $\checkmark$ \\
\hline
\end{tabular}

Acknowledgement

The authors are grateful to Big River Pork for their generous donation of porcine ovaries. Financial support was provided from the National Health and Medical Research Council and the Juvenile Diabetes Research Foundation. WK was a recipient of a Cooperative Research Centre for an Internationally Pork Industry Honours scholarship.

\section{Publication history}

Editor: Kameshwar Prasad Singh, University of Rochester, USA. Received: 08-Nov-2013 Revised: 16-Dec-2013

Accepted: 31-Dec-2013 Published: 08-Jan-2014

\section{References}

1. Evans MJ and Kaufman MH. Establishment in culture of pluripotential cells from mouse embryos. Nature. 1981; 292:154-6. | Article | PubMed

2. Martin GR. Isolation of a pluripotent cell line from early mouse embryos cultured in medium conditioned by teratocarcinoma stem cells. Proc Natl Acad Sci U S A. 1981; 78:7634-8. | Article | PubMed Abstract | PubMed Full Text

3. Brevini TA and Gandolfi F. Parthenotes as a source of embryonic stem cells. Cell Prolif. 2008; 41 Suppl 1:20-30. | Article | PubMed

4. Kaufman MH, Robertson EJ, Handyside AH and Evans MJ. Establishment of pluripotential cell lines from haploid mouse embryos. J Embryol Exp Morphol. 1983; 73:249-61. | Article | PubMed

5. Kim K, Lerou P, Yabuuchi A, Lengerke C, Ng K, West J, Kirby A, Daly MJ and Daley GQ. Histocompatible embryonic stem cells by parthenogenesis. Science. 2007; 315:482-6. | Article | PubMed

6. Chen Z, Liu Z, Huang J, Amano T, Li C, Cao S, Wu C, Liu B, Zhou L, Carter $M G$, Keefe DL, Yang $X$ and Liu L. Birth of parthenote mice directly from parthenogenetic embryonic stem cells. Stem Cells. 2009; 27:2136-45. | Article I PubMed

7. Allen ND, Barton SC, Hilton $\mathrm{K}$, Norris $\mathrm{ML}$ and Surani MA. A functional analysis of imprinting in parthenogenetic embryonic stem cells. Development. 1994; 120:1473-82. | Article | PubMed

8. Somfai T, Ozawa M, Noguchi J, Kaneko H, Ohnuma K, Karja NW, Fahrudin M, Maedomari N, Dinnyes A, Nagai T and Kikuchi K. Diploid porcine parthenotes produced by inhibition of first polar body extrusion during in vitro maturation of follicular oocytes. Reproduction. 2006; 132:55970. | Article | PubMed

9. Kubiak J, Paldi A, Weber M and Maro B. Genetically identical parthenogenetic mouse embryos produced by inhibition of the first meiotic cleavage with cytochalasin D. Development. 1991; 111:763-9. | Pdf I PubMed

10. Jarett $L$ and Smith RM. Effect of cytochalasin $B$ and $D$ on groups of insulin receptors and on insulin action in rat adipocytes. Possible evidence for a structural relationship of the insulin receptor to the glucose transport system. J Clin Invest. 1979; 63:571-9. | Article | PubMed Abstract | PubMed Full Text

11. Vassiliev I, Vassilieva S, Beebe LF, Harrison SJ, Mcllfatrick SM and Nottle $\mathrm{MB}$. In vitro and in vivo characterization of putative porcine embryonic stem cells. Cell Reprogram. 2010; 12:223-30. | Article | PubMed 
Vassiliev et al. Stem Cell Biology and Research 2014,

http://www.hoajonline.com/journals/pdf/2054-717X-1-2.pdf

12. Vassiliev I, Vassilieva S, Beebe LF, Mcllfatrick SM, Harrison SJ and Nottle $\mathrm{MB}$. Development of culture conditions for the isolation of pluripotent porcine embryonal outgrowths from in vitro produced and in vivo derived embryos. J Reprod Dev. 2010; 56:546-51. I Article I PubMed

13. Vassiliev I, Vassilieva S, Truong KP, Beebe LF, Mcllfatrick SM, Harrison $\mathrm{SJ}$ and Nottle MB. Isolation and in vitro characterization of putative porcine embryonic stem cells from cloned embryos treated with trichostatin A. Cell Reprogram. 2011; 13:205-13. | Article | PubMed

14. Beebe L, Mcllfatrick S, Grupen C, Boquest A, Harrison S, Faast R, Ashman $\mathrm{R}$, Wengle J, Hamilton $\mathrm{H}$ and Nottle $\mathrm{M}$. A comparison of two in vitro maturation media for use with adult porcine oocytes for adult somatic cell nuclear transfer. Cloning Stem Cells. 2007; 9:564-70. | Article | PubMed

15. Kuhholzer B, Hawley RJ, Lai L, Kolber-Simonds D and Prather RS. Clonal lines of transgenic fibroblast cells derived from the same fetus result in different development when used for nuclear transfer in pigs. Biol Reprod. 2001; 64:1695-8. | Article | PubMed

16. Beebe LF, Mcllfactrick S and Nottle MB. The effect of energy substrate concentration and amino acids on the in vitro development of preimplantation porcine embryos. Cloning Stem Cells. 2007; 9:206-15. I Article | PubMed

17. Petters RM and Wells KD. Culture of pig embryos. J Reprod Fertil Suppl. 1993; 48:61-73. I PubMed

18. Macfarlane WM, McKinnon CM, Felton-Etkins ZA, Cragg $\mathrm{H}$, James RF and Docherty K. Glucose stimulates translocation of the homeodomain transcription factor PDX1 from the cytoplasm to the nucleus in pancreatic b-cells. J. Biol. Chem. 1999; 274:1011-1016. | Article

19. Krupkova O, Jr., Loja T, Redova M, Neradil J, Zitterbart K, Sterba J and Veselska R. Analysis of nuclear nestin localization in cell lines derived from neurogenic tumors. Tumour Biol. 2011; 32:631-9. | Article | PubMed

20. Thomas SK, Messam CA, Spengler BA, Biedler JL and Ross RA. Nestin is a potential mediator of malignancy in human neuroblastoma cells. J Biol Chem. 2004; 279:27994-9. | Article I PubMed

21. Sugimura S, Kawahara M, Wakai T, Yamanaka K, Sasada $H$ and Sato E. Effect of cytochalasins B and D on the developmental competence of somatic cell nuclear transfer embryos in miniature pigs. Zygote. 2008; 16:153-9 | Article | PubMed

22. Suzuki $H$ and Saito Y. Cumulus cells affect distribution and function of the cytoskeleton and organelles in oocytes. Reprod. Med Biol 2006; 5:183-194. | Article

23. Brevini TA, Pennarossa G, Maffei S, Tettamanti G, Vanelli A, Isaac S, Eden A, Ledda S, de Eguileor M and Gandolfi F. Centrosome amplification and chromosomal instability in human and animal parthenogenetic cell lines. Stem Cell Rev. 2012; 8:1076-87. | Article | PubMed

24. Brevini TAL, Cillo F and Gandolfi F. Establishment and molecular characterization of pig parthenogenetic embryonic stem cells. Reprod Fert and Dev. 2005; 17:235-235. I Pdf

25. Xu XM, Hua JL, Jia WW, Huang W, Yang CR and Dou ZY. Parthenogenetic activation of porcine oocytes and isolation of embryonic stem cells-like derived from parthenogenetic blastocysts. Asian-Aust J Anim Sci . 2007; 20:1510-1516. | Pdf

\section{Citation:}

Vassiliev I, Tsui A, Xian Kang W, McIlfatrick S and Nottle MB. Effect of cytochalasin types on the production of heterozygous parthenogenetic porcine embryos and the isolation of putative parthenogenetic embryonic stem cells. Stem Cell Biol Res. 2014; 1:2.

http://dx.doi.org/10.7243/2054-717X-1-2 